\title{
Influences of cold exposure on digestion of organic matter, rates of passage of digesta in the gastrointestinal tract, and feeding and rumination behaviour in sheep given four forage diets in the chopped, or ground and pelleted form
}

\author{
BY P. M. KENNEDY* \\ Department of Animal Science, The University of Alberta, Edmonton, \\ Alberta T6G 2P5, Canada
}

(Received 25 April 1984 - Accepted 13 August 1984)

1. Sixteen sheep, each fitted with cannulas in the rumen and proximal duodenum, were given four diets in the chopped or ground and pelleted form, at fixed intakes at intervals of $2 \mathrm{~h}$. The sheep were closely shorn and exposed to temperatures of $22-25^{\circ}$ or $1-4^{\circ}$ for four periods of $45 \mathrm{~d}$. Flow of duodenal digesta by reference to the markers CoEDTA and ${ }^{103} \mathrm{Ru}$-phenanthroline, chewing behaviour and particle size of rumen and duodenal digesta were measured.

2. Apparent digestibility of organic matter (OM) in the gastrointestinal tract was depressed $(P<0 \cdot 05)$ by grinding and pelleting the diet, and by exposure of sheep to cold ambient temperatures. This was attributable to depression $(P<0.01)$ by 0.1 of OM digestion in the reticulo-rumen. No effects on intestinal digestion of OM were observed.

3. Cold ambient temperatures did not affect the content, but increased the rate of digestion for pelleted diets but not for chopped diets, of potentially-degradable cell-wall constituents of ground dietary material incubated in nylon-bags in the rumen.

4. Retention times of markers of the particulate and liquid phases of rumen digesta were not significantly $(P<0.05)$ affected by ambient temperature, despite significant $(P<0.001)$ increases in the rate of contraction of the reticulum. Retention time of ${ }^{103} \mathrm{Ru}$-phenanthroline in the intestines was not affected by cold exposure.

5. Cold exposure was associated with depression $(P<0.05)$ of volatile fatty acids concentration in the rumen and elevated $(P<0.05) \mathrm{pH}$. Molar proportions of acetic and isovaleric acid were reduced $(P<0 \cdot 01)$, accompanied by increased $(P<0.001)$ proportions of propionic acid during cold exposure.

6. Cold exposure and pelleting of the diets were both associated with reduction in digesta particle size in the rumen. Duodenal particle size was not affected by cold exposure. Pelleting of the diet markedly reduced $(P<0.001)$ duration of chewing and number of chews/d during eating and rumination. Cold exposure of sheep resulted in a faster $(P<0.01)$ rate of eating of the diets.

7. When allowed to express their voluntary feed consumption during a $10 \mathrm{~d}$ period, intakes of chopped diets were increased by $0.13(P<0.01)$ by cold exposure, in contrast to lack of significant change in sheep given pellets.

8. The results did not support the hypothesis that the effect of cold exposure on digestion was dependent on the physical form of the diet given at fixed intake, but did indicate that increased voluntary feed consumption was a result of increased clearance of digesta from the rumen through decreased rumen particle size and increased reticulum motility.

The association of cold exposure with increased frequency of biphasic contractions of the reticulum (Westra \& Christopherson, 1976) has provided a convenient method to study the metabolic consequences of an increased rate of passage of digesta from the rumen. For sheep given pelleted brome grass (Bromus inermis) these consequences have included a reduction in digestion of organic matter (OM) and cell-wall constituents (CWC) in the rumen and in the whole gastrointestinal tract, and an increase in fractional turnover rate of markers of the solid and liquid phases of rumen digesta (Kennedy et al. 1976; Kennedy \& Milligan, 1978). However, with sheep given lucerne (Medicago sativa) or brome grass in the chopped form at warm and cold temperatures, the reduction in $\mathrm{OM}$ digestion in the rumen associated with cold exposure was not as marked as previously obtained with pelleted diets (Kennedy et al. 1982). The latter authors suggested that the rates of digestion and comminution of

* Present address : Division of Tropical Animal Science, CSIRO, PMB, Aitkenvale, Queensland 4814, Australia. 
coarse particulate material in rumen digesta could be responsible for interactions between temperature and form of diet in the digestive indices measured.

The present experiment was designed to compare directly rates of passage and digestion of four forage diets offered in the chopped or ground and pelleted forms at restricted intakes to sheep exposed to warm and cold ambient temperatures. In particular, measurements of chewing behaviour during eating and rumination and of digesta particle size were made in order to determine whether increased voluntary feed consumption in animals exposed to cold was associated with changes in rates of comminution of large digesta particles. In addition, the present paper reports results of studies of marker retention time in the stomach and intestines, $\mathrm{OM}$ digestion, and of rate of disappearance of dietary material from nylon bags incubated in the rumen.

\section{EX PER I MENT A L}

\section{Animals and management}

Sixteen Suffolk wethers, 11-12 months of age and weighing 32-42 kg were used. Each sheep was fitted with permanent cannulas in the rumen and proximal duodenum, and was housed in a metabolism cage with continuous lighting at ambient temperatures of $22-25^{\circ}$ (warm) or $1-4^{\circ}$ (cold). Sheep were closely shorn at the beginning, and after $18 \mathrm{~d}$, of each $45 \mathrm{~d}$ period. After 25 and $32 \mathrm{~d}$ of temperature exposure, ambient temperatures were reduced by $1^{\circ}$ to compensate for wool growth. Intramuscular injections $(\mathrm{mg})$ of retinol $0 \cdot 75$, cholecalciferol 0.94 and $\alpha$-tocopherol 16 were made at intervals of $14 \mathrm{~d}$.

\section{Diets and feeding}

Four hay diets were prepared in two forms by either grinding through a $75 \mathrm{~mm}$ screen or by grinding through a $3.2 \mathrm{~mm}$ screen and pelleting. Lucerne (Medicago sativa L.) was harvested at the mid-bloom stage. Red clover (Trifolium pratense L.), reed canary grass (Phalaris arudinacea L.) and brome grass (Bromus inermis Leyss) were harvested at late bloom. All diets were judged to contain $5 \%$ of other species. The red clover suffered substantial loss of flower and leaf during baling. The chemical composition of the diets is shown in Table 1. Each diet was given at intervals of $2 \mathrm{~h}$ to provide intake equal to 0.90 that of the sheep given the chopped form of the diet at warm ambient temperatures, as determined in a preliminary experiment. Water and cobalt-iodized salt was provided ad lib.

\section{Experimental design and schedule}

Each group of four sheep received each forage species for a total of $180 \mathrm{~d}$. During four periods, each of $45 \mathrm{~d}$, each sheep received the chopped or pelleted form at alternatively warm and cold ambient temperatures, in a split-block design. After $21 \mathrm{~d}$ adaptation, a total faecal collection was made daily for $7 \mathrm{~d}$. In addition, on day 24 , a dose of ${ }^{103} \mathrm{Ru}$-phenanthroline $\left({ }^{103} \mathrm{Ru}-\mathrm{P}\right.$; Tan et al. 1971) in duodenal digesta was injected $(0.4 \mathrm{MBq} / \mathrm{ml}, 5 \mathrm{ml})$ into the duodenal cannula with a close-fitting plastic syringe. After $10 \mathrm{~min}$ the syringe was removed and any residual dose was washed into the duodenum with $10 \mathrm{ml}$ water. Faecal samples were taken from the rectum at $3,6,9,12,15,18,24,30$ and $36 \mathrm{~h}$ after dosing, in order to determine the retention time of ${ }^{103} \mathrm{Ru}-\mathrm{P}$ in the post-duodenal tract. Measurements of feeding and rumination behaviour were made over $24 \mathrm{~h}$ during days 24-28 using a microswitch mounted on a head halter, connected to a digital counter and chart recorder. Frequency of biphasic contraction of the reticulum was measured over $4 \mathrm{~h}$ using a pressure transducer and open-tipped catheter located in the reticulum.

On day 28 , a primed continuous infusion of markers $(20 \mathrm{ml} / \mathrm{h})$ into the rumen was made for $6.5 \mathrm{~d}$. The infusion solution contained ${ }^{103} \mathrm{Ru}-\mathrm{P}(0.80 \mathrm{MBq}, 6 \mu \mathrm{g} \mathrm{Ru} / \mathrm{l}),\left({ }^{15} \mathrm{NH}_{4}\right)_{2} \mathrm{SO}_{4}$ $\left(80 \mathrm{mg}{ }^{15} \mathrm{~N} / 1,0.98\right.$ atoms ${ }^{15} \mathrm{~N} /$ atom $\mathrm{N}$ ) and CoEDTA (Co complexed with EDTA by the 
Table 1. Diet content $(\mathrm{g} / \mathrm{kg}$ dry matter $(D M))$ of nitrogen, organic matter $(O M)$ and acid-detergent fibre $(A D F)$ and particle size distribution of four forage diets in the chopped or ground and pelleted form

\begin{tabular}{|c|c|c|c|c|c|c|c|c|}
\hline \multirow{2}{*}{$\begin{array}{l}\text { Diet... } \\
\text { Form of diet... }\end{array}$} & \multicolumn{2}{|c|}{ Lucerne } & \multicolumn{2}{|c|}{ Red clover } & \multicolumn{2}{|c|}{ Canary grass } & \multicolumn{2}{|c|}{ Brome grass } \\
\hline & Chopped & Pelleted & Chopped & Pelleted & Chopped & Pelleted & Chopped & Pelleted \\
\hline $\mathrm{N}$ content & 23.6 & $23 \cdot 1$ & $18 \cdot 3$ & $18 \cdot 2$ & $14 \cdot 7$ & $14 \cdot 2$ & 13.9 & 14.9 \\
\hline OM content & 857 & 860 & 891 & 888 & 868 & 885 & 904 & 891 \\
\hline ADF content & 290 & 303 & 391 & 378 & 366 & 417 & 349 & 354 \\
\hline $\log \mu^{*}$ & 3.978 & 2.939 & $4 \cdot 224$ & $2 \cdot 895$ & $4 \cdot 420$ & $2 \cdot 812$ & $4 \cdot 297$ & $2 \cdot 811$ \\
\hline $\log \sigma^{*}$ & 0.770 & 0.486 & 0.689 & 0.419 & 0.797 & 0.515 & 0.713 & 0.451 \\
\hline $\begin{array}{l}R^{2} \text { of log-normal } \\
\text { regression }\end{array}$ & 0.96 & 0.98 & 0.99 & 0.98 & 0.96 & 1.00 & 0.99 & $1 \cdot 00$ \\
\hline
\end{tabular}

* $\log _{10}$ mean particle size $(\log \mu)$ and $\log _{10}$ standard deviation $(\log \sigma)$ of logarithmic-normal regression calculated as described by Waldo et al. (1971).

method of Uden et al. $1980,440 \mathrm{mg} \mathrm{Co} / \mathrm{l})$. The priming dose $(5 \mathrm{ml})$ contained all markers in amounts equivalent to $10 \mathrm{~h}$ of continuous infusion. After $40 \mathrm{~h}$ of intraruminal infusion, nylon bags $(53 \mu \mathrm{m}$ porosity, Nitex nylon screen cloth, Tetko Inc., Elmsford, NY 10523, USA) containing three glass marbles and the diet $(3 \mathrm{~g})$ ground through a $3 \mathrm{~mm}$ screen, were sequentially inserted in duplicate into the rumen to given incubation times of $3,6,12,18$, 24 and $48 \mathrm{~h}$. On removal from the rumen, the bags were briefly washed to remove adhering digesta, and were then individually washed by manipulation for $1 \mathrm{~min}$ in warm water, until the washings were colourless.

Four samples ( $50 \mathrm{ml}$ ) of duodenal digesta were collected on each of days 31-33 at intervals of $4 \mathrm{~h}$ between $08.00-20.00$ hours. At the same time, samples $(30 \mathrm{ml})$ of rumen fluid were removed and divided into three samples for Co and volatile fatty acids (VFA) analysis, and for ${ }^{15} \mathrm{~N}$ estimation (not reported here). The subsamples were bulked within sheep and immediately frozen. An additional sample $(50 \mathrm{ml})$ of rumen fluid was taken on days 32-34 for the immediate measurement of $\mathrm{pH}$.

On day 34 a dose $(1.8 \mathrm{MBq})$ of ${ }^{51} \mathrm{Cr}$-labelled medium particles $\left({ }^{51} \mathrm{Cr}-\mathrm{MP}\right)$ was given, $12 \mathrm{~h}$ before the intraruminal infusion of markers was stopped. ${ }^{51} \mathrm{Cr}$-MP were prepared from samples of each diet ground through a $1 \mathrm{~mm}$ screen, by the method of Uden et al. (1980) but with the addition of $\mathrm{Na}_{2}{ }^{51} \mathrm{Cr}_{2} \mathrm{O}_{7}$. Seven samples of rumen fluid and of duodenal digesta were taken at intervals of $2 \mathrm{~h}$ on day 35 in order to calculate the fractional turnover rate of CoEDTA in rumen fluid and of ${ }^{103} \mathrm{Ru}-\mathrm{P}$ and ${ }^{51} \mathrm{Cr}$-MP in duodenal digesta. After the final sample, a large sample $(300 \mathrm{ml})$ of rumen digesta for particle fractionation by wet sieving was obtained from each sheep using a hollow tube, $20 \mathrm{~mm}$ in diameter, of which the lower end could be sealed within the rumen.

Between days 36 and 45 , the quantity of feed offered to individual sheep was increased to an amount $1 \cdot 1-1 \cdot 2$ of consumption during the previous day. A portion $(0 \cdot 2)$ of the daily allotment was given at 09.00 hours after removing residues from the previous day. The remainder was given by automatic feeder at intervals of $2 \mathrm{~h}$. The mean daily quantity eaten during the final $6 \mathrm{~d}$ of the period was used to estimate voluntary feed consumption.

\section{Behavioural activities}

Total daily jaw movements were divided into eating, incidental, and rumination chews by observation of the sheep during seven meals, with recording of the number of chews during eating, and of incidental chews which occurred mainly immediately after meals. The average 
number of chews/rumination cycle recorded during $07.00-19.00$ hours was used to calculate daily rumination chews from the chart record of rumination cycles (boluses).

\section{Analytical procedures}

Dry matter (DM), OM, cell-wall constituents, acid-detergent fibre (ADF), N, ${ }^{51} \mathrm{Cr}$ and ${ }^{103} \mathrm{Ru}$ were determined as described previously (Kennedy et al. 1982).

Co was measured by atomic absorption spectrophotometry (model 4000; Perkin Elmer Corp., Norwalk, Conn. 06856, USA) after ashing of samples, boiling with nitric acid ( $25 \mathrm{ml}$, $30 \mathrm{~min})$ and addition when cold of perchloric acid $(72 \%, 10 \mathrm{ml})$ before dilution.

Samples $(100 \mathrm{~g})$ of rumen and duodenal digesta were subjected to a wet-sieving technique with screens of 4, 2, 1, 0.50 and 0.25 mm (see Dixon \& Milligan, 1985).

VFA were separated using a gas-liquid chromatograph (model 2500; Bendix Process Instruments Div., Ronceverte, W. VA, USA) with a column packed with Chromosorb 101 (Supelco Corp., Bellefonte, PA, USA). A hydrogen flame-ionization detector was used. Total VFA content was estimated by use of $n$-caproic acid as an internal standard after establishing that this compound was absent in the sample.

\section{Calculations and statistical analysis}

Movement of digesta in the proximal duodenum was calculated by reference to the content of ${ }^{103} \mathrm{Ru}-\mathrm{P}$ and CoEDTA in digesta, corrected for absorption of Co from the reticulo-rumen, assumed to be 0.5 of the appearance of Co in the urine on day 30 (see Faichney, 1975).

Rumen-fluid volume and mean retention times of CoEDTA, ${ }^{103} \mathrm{Ru}-\mathrm{P}$ and ${ }^{51} \mathrm{Cr}-\mathrm{MP}$ were calculated assuming first-order kinetics (Shipley \& Clark, 1972). Retention time of ${ }^{103} \mathrm{Ru}-\mathrm{P}$ in the post duodenal tract was calculated using eqn (9) of Faichney (1975).

The disappearance $\left(\mathrm{P}_{1}+\mathrm{P}_{2}\right)$ of CWC from nylon bags with time in the rumen was described by two equations of the form:

$$
\begin{aligned}
& P_{1}=a, \text { up to time } t_{0}, \\
& P_{2}=a^{\prime}+b^{\prime}\left(1-\mathrm{e}^{-c t}\right), \text { from time } t_{0} \text { onwards (McDonald, 1981), }
\end{aligned}
$$

where $a$ is the rapidly-degradable fraction and $c$ is the rate of digestion from time $t_{0}$ onwards of the slowly-degradable fraction $\left(a^{\prime}+b^{\prime}-a\right)$.

$\log _{10}$ mean particle size $(\log \mu)$ and its $\log _{10}$ standard deviation $(\log \sigma)$ of particulate digesta were calculated from the particulate DM distribution determined by wet sieving. The cumulative percentage of particulate DM was probit (normal equivalent deviates increased by the addition of 5.0), transformed (Sokal \& Rohlf, 1969) and regressed against $\log _{10}$ sieve aperture $(\mu \mathrm{m}) . \log \mu$ was estimated by solving regressions at probit 5 . $\log \sigma$ of the distribution was calculated as the inverse of the regression slope (Waldo et al. 1971).

Variables were analysed as a split-block design for effects of diet, form of diet, period, temperature, form $\times$ temperature and diet (sheep unit) $\times$ period interactions. Diets were tested against sheep within diets. Period, temperature, form and interactions were tested against residual mean squares ( $33 \mathrm{df}$ ). Other diet interactions were confounded with sheep units and were generally non-significant; accordingly they were pooled in the error term. Differences between temperatures within diets were tested for significance by $t$ test.

\section{RESULTS}

\section{Flow of $O M$ and $C W C$ in the gastrointestinal tract}

Intakes by sheep of $O M$ for lucerne, red clover and reed-canary diets were fixed at between 1058 and $1162 \mathrm{~g} / \mathrm{d}$, in contrast to lower amounts, $927-929 \mathrm{~g} / \mathrm{d}$, of brome grass (Table 2). In addition to differences attributable to diet, the apparent $O M$ digestibility of pelleted diets 
Digestion and chewing in cold sheep

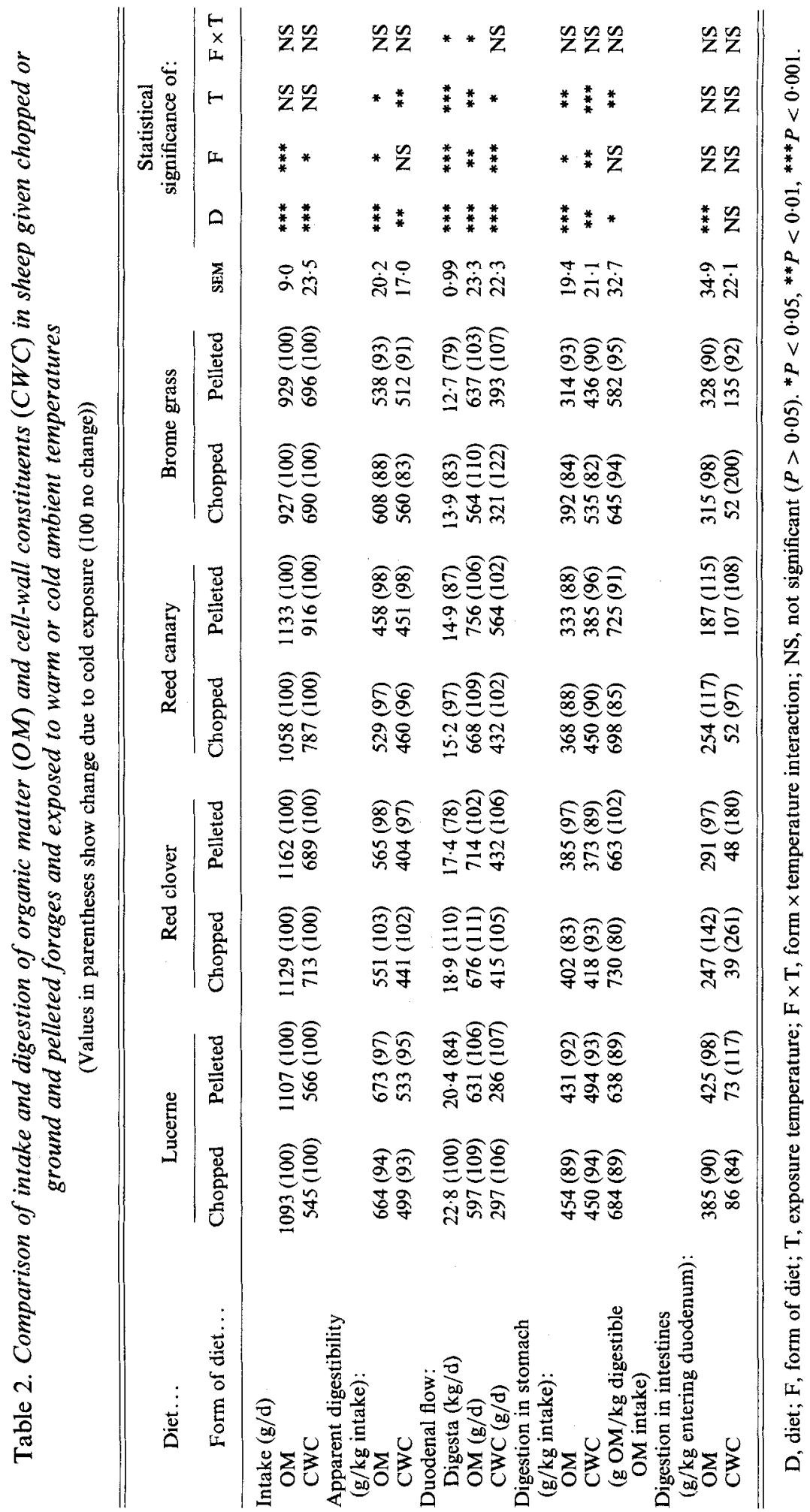


was less $(P<0.05)$ than for the chopped form. Exposure of closely-shorn wether sheep to cold resulted in significant declines in apparent digestibility of OM $(P<0.05)$ and CWC $(P<0.01)$, with the decrease being most pronounced for the brome-grass diet, and insignificant for the clover diet (Table 2).

Grinding and pelleting of the diets resulted in decreased digesta flow $(P<0.001)$ but increased flow of $\mathrm{OM}$ and $\mathrm{CWC}$ to the duodenum. Cold exposure significantly decreased the rate of flow of digesta $(P<0.001)$ but increased $(P<0.05)$ that of $\mathrm{OM}$ and $C W C$ into the duodenum. The responses to cold exposure in digesta and OM flow to the duodenum were more pronounced for pelleted diets than for chopped diets, as indicated by significant $(P<0.05)$ form $\times$ temperature interactions (Table 2). Digestibilities of $\mathrm{OM}$ and $\mathrm{CWC}$ in the intestines were not affected by cold stress.

\section{Nylon-bag studies}

The rate of CWC disappearance from nylon bags was higher for the legumes than for the grasses (Table 3 ). The rate of CWC disappearance was not significantly affected by cold exposure in sheep given chopped diets, but was increased $(P<0.05)$ to $1.06-1.31$ of the rate of warm sheep for animals given the pelleted diets at the low ambient temperature.

More of the CWC of grasses than of legumes were potentially degradable, as indicated by the asymptote of digestion in nylon bags. Grinding and pelleting resulted in an increase by 0.1 of potentially available CWC (Table 3 ). Potentially-degradable CWC were reduced $(P<0.05)$ by 0.14 by cold-exposure in sheep given clover pellets. Comparison of measured CWC digestion in the gastrointestinal tract with potentially-degradable CWC indicated that digestion of chopped legume CWC was essentially complete. In contrast, approximately 0.15 of potentially-digestible CWC in chopped grass escaped digestion in the gastrointestinal tract (Tables 2 and 3).

\section{Retention time, motility, VFA and particle size in the rumen}

Cold exposure did not affect rumen retention times of ${ }^{103} \mathrm{Ru}-\mathrm{P},{ }^{51} \mathrm{Cr}-\mathrm{MP}$ or CoEDTA markers. ${ }^{51} \mathrm{Cr}$-MP was retained longer $(P<0.01)$ when diets were given in pelleted form than as chopped hay. Retention time of ${ }^{103} \mathrm{Ru}-\mathrm{P}$ in the post-duodenal tract was not affected by ambient temperature (Table 3 ).

Pelleting of diets depressed $(P<0.05)$, and cold stress increased $(P<0.001)$, reticulum motility (Table 3). Per reticulum contraction, flow of DM and CWC at the duodenum differed $(P<0.01)$ between diets and was greater $(P<0.001)$ when sheep were given pelleted rather than chopped diets. Cold exposure significantly $(P<0.01)$ reduced the flow of DM to the duodenum per reticulum contraction, by approximately 0.07 (Table 3 ).

Cold exposure caused significant $(P<0.001)$ increases in $\mathrm{pH}$ and molar proportion of propionic acid, and significant decreases $(P<0.05)$ in VFA concentration and molar proportion of isovaleric acid (Table 4). Differences between diets were observed for VFA concentration and molar proportions of acetic, butyric, isovaleric and valeric acids (Table 4).

Cold exposure significantly decreased the large-particle content, the medium/medium plus fine $(0.5-1.0 /<1.0 \mathrm{~mm})$ fraction, and $\log \mu$ of rumen digesta, but no differences with temperature in large-particle content or $\log \mu$ of duodenal digesta were observed (Table 5). The large particle and $\log \mu$ contents of digesta from both sites were significantly affected $(P<0.05)$ by diet, with values from duodenal digesta of sheep given clover being considerably higher $(P<0.05)$ than for the other diets. Pelleting of diets significantly $(P<0.001)$ reduced the proportion of large particles in rumen and duodenal digesta, and of $\log \sigma$ and medium/medium plus fine particles in duodenal and rumen digesta respectively. $\log \mu$ in rumen digesta was poorly correlated $\left(r^{2}-0.01\right)$ with $\log \mu$ in duodenal digesta, 
Digestion and chewing in cold sheep

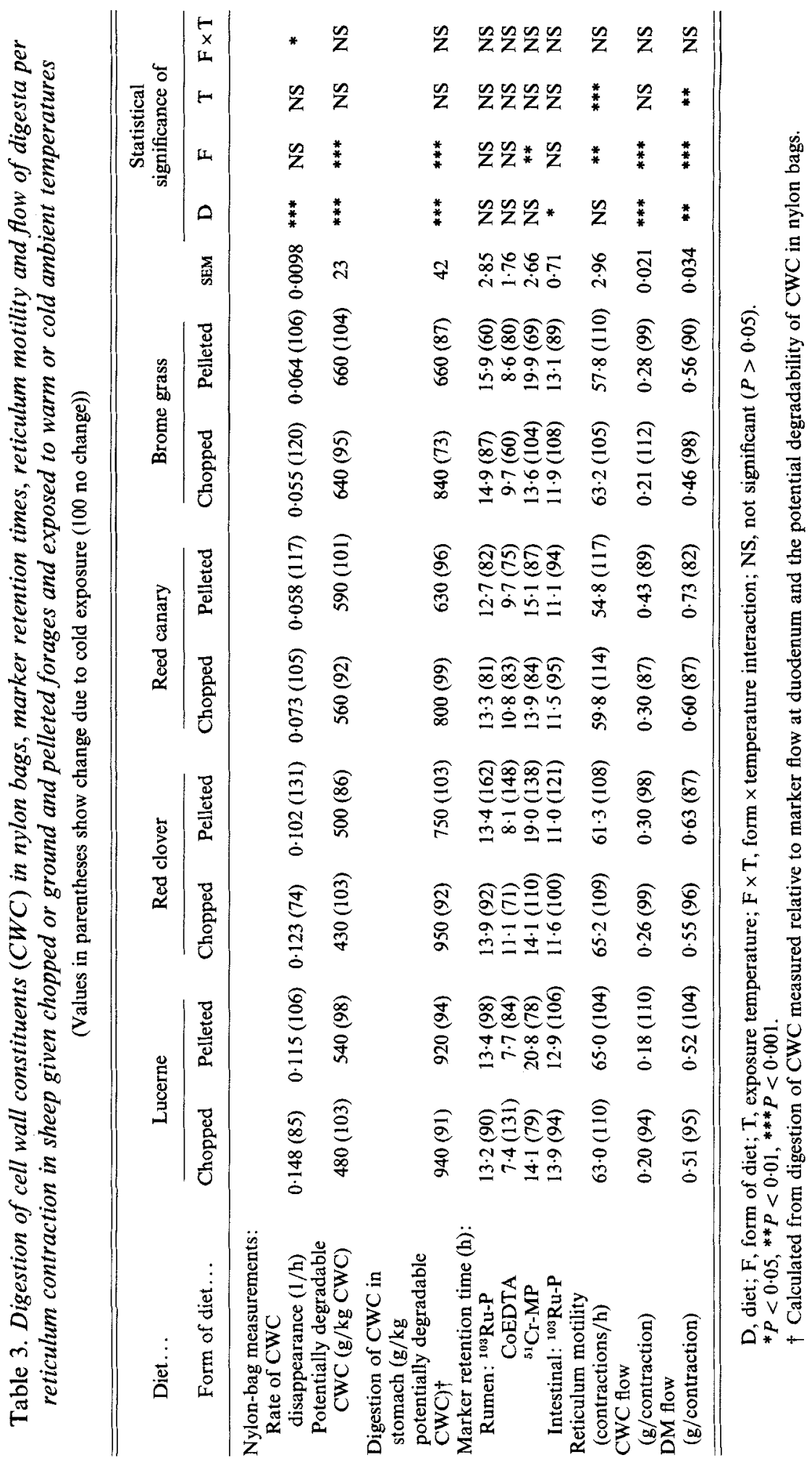


Digestion and chewing in cold sheep

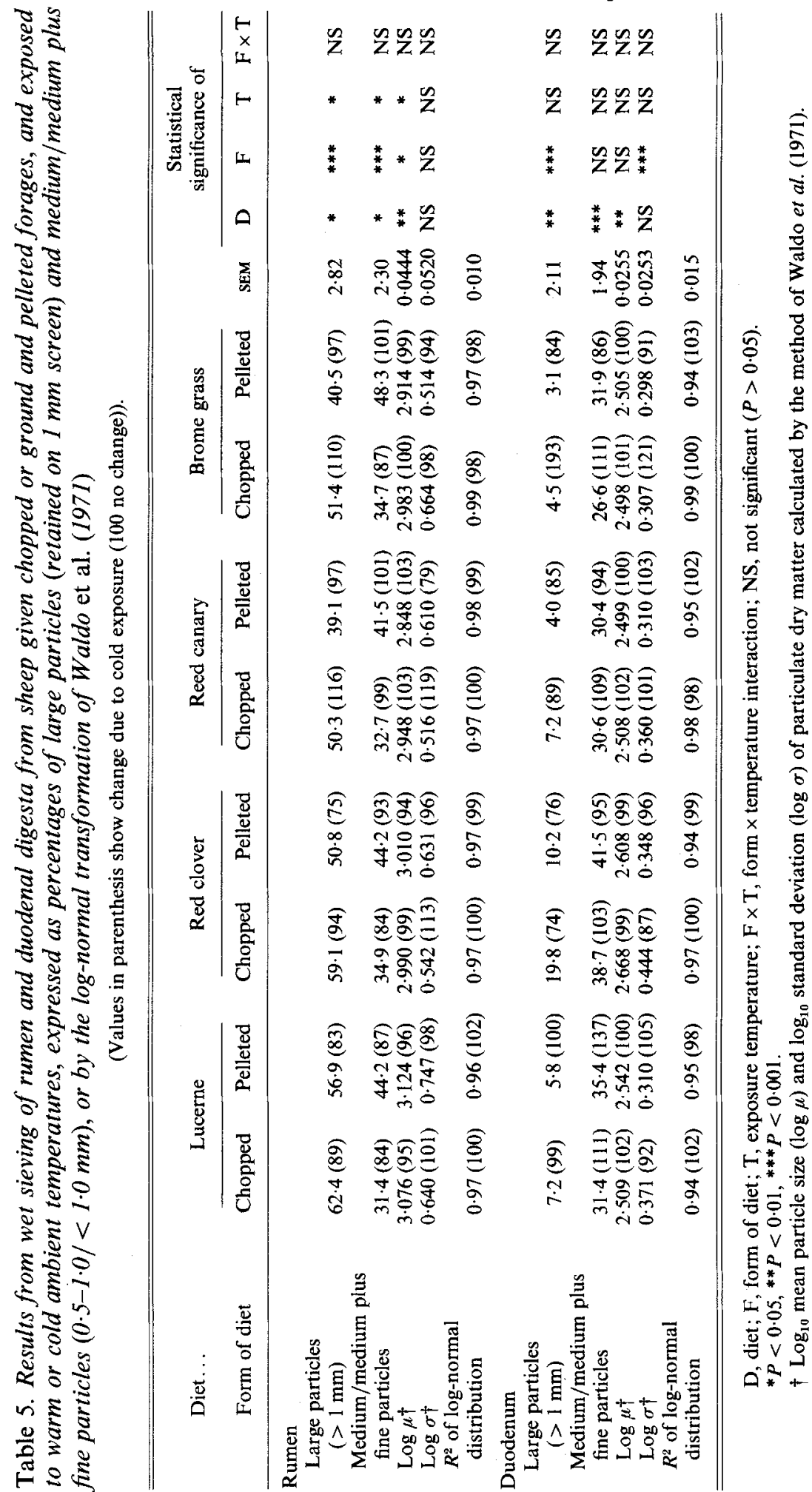




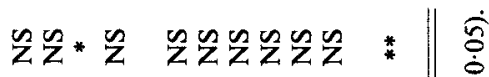

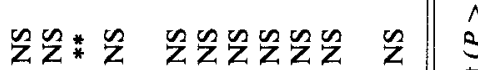

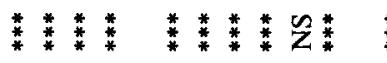

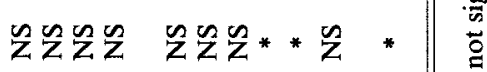

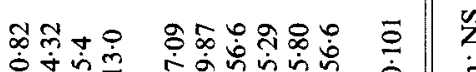

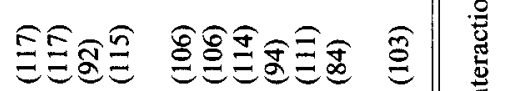

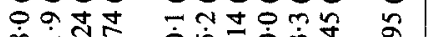

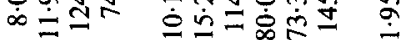

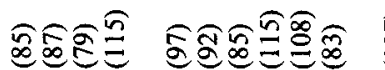

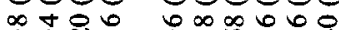

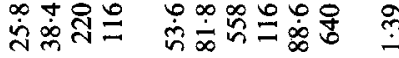

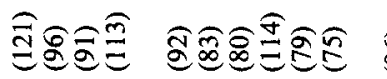

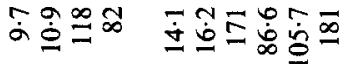

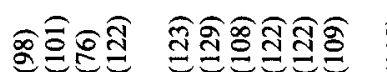

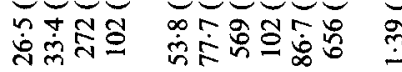

居可氞

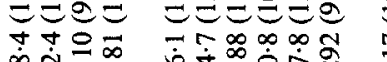

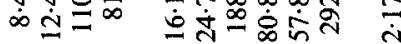

宓

更

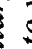

ฐ

胥

कृ

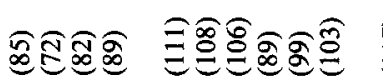

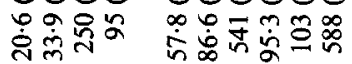

象余

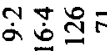

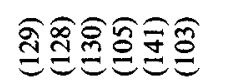

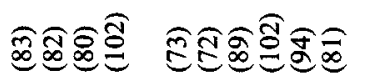

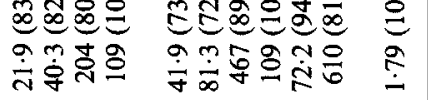


and with $\log \sigma$ of rumen digesta in sheep given chopped hay $\left(r^{2} 0.04, n 32\right)$ but the latter were better correlated in sheep given pellets $\left(r^{2} 0.58, n 32\right)$.

\section{Chewing behaviour and voluntary feed consumption}

Eating behaviour of warm-exposed sheep given chopped diets was relatively constant across diets, at 20.6-26.5 $\times 10^{3}$ chews $/ \mathrm{d}, 33.4-40.3$ chews $/ \mathrm{g}$ CWC intake, and 204-272 min/d of duration (Table 6). Cold exposure significantly reduced $(P<0.01)$ duration of eating, with the reduction being more marked $(P<0.05)$ for the chopped form of the diet. Grinding and pelleting the diets resulted in marked reductions $(P<0.001)$ in number of chews $/ \mathrm{d}$, duration of chewing and chews/min.

Rumination behaviour was characterized by $41 \cdot 9-57 \cdot 8 \times 10^{3}$ chews/d, 588-656 cycles/d, requiring $467-569 \mathrm{~min} / \mathrm{d}$ in sheep given chopped diets at warm temperatures (Table 6). Significant differences $(P<0.05)$ due to diet were observed for chews/min and chews/cycle. Pelleting of diets significantly reduced $(P<0.001)$ chews $/ \mathrm{d}$, chews $/ \mathrm{g}$ CWC intake, duration and number of cycles, but rumination still occupied $2-3 \mathrm{~h} / \mathrm{d}$. Cold exposure did not affect $(P>0.05)$ any of the measured indices of rumination.

Voluntary feed consumption of chopped lucerne was higher $(P<0.05)$ for warm-exposed sheep (Table 6). Grinding and pelleting of the diets resulted in increases of $0.3-0.6$ $(P<0.001)$. Cold exposure resulted in increased $(P<0.01)$ intake of chopped diets by approximately $0 \cdot 13$, but did not significantly affect intake of the pelleted diets during the $10 \mathrm{~d}$ of $a d$ lib. feeding.

\section{DISCUSSION}

\section{Digestion of $O M$}

The hypothesis that the digestive responses to increases in reticulum motility associated with cold stress were dependent on the form of the diet was not supported by the results obtained in the experiment reported here. Indeed, the apparent digestion of lucerne, reed canary or brome grass OM was reduced by similar amounts for both pelleted and chopped forms of the diets, to $0.84-0.93$ in the rumen and to $0.88-0.98$ in the entire gastrointestinal tract of values measured for warm sheep. For those diets, the effect of grinding and pelleting on increasing OM flow from the stomach was similar to that previously found (Thomson \& Beever, 1980). In addition, the greater depression of OM digestion in the stomach caused by pelleting of grasses compared with legumes is in agreement with other studies (Thomson \& Beever, 1980).

Apparent digestibility of clover OM was not significantly affected by cold exposure, despite decreases in $\mathrm{OM}$ digestion in the stomach with chopped clover which were comparable to those seen during cold struss in sheep given the other three diets. This appeared to be due to the capacity of the intestines to compensate for decreased rumen digestion of red clover, as discussed later.

\section{Marker retention time and digestion in the rumen}

Results from previous experiments from this laboratory have suggested an increased rate of passage of dietary residues from the rumen caused by enhanced contraction rate of the reticulum during cold exposure (Westra \& Christopherson, 1976; Kennedy et al. 1976; Kennedy \& Milligan, 1978; Gonyou et al. 1979; Kennedy et al. 1982). The present results are consistent with this, except for those for sheep given clover pellets, in which retention time of markers was increased in cold-exposed sheep, despite typical increases in reticulum motility and passage of digesta from the abomasum. For the latter diet, the increase $(0.38-0.62)$ in particulate-marker retention time was greater than that $(0.06)$ of CWC flowing into the duodenum when sheep were exposed to low ambient temperatures, 
suggesting that the rumen pool of particulate matter was increased. Increased pool size and the decreased availability of CWC in pelleted clover for digestion in nylon bags from 500 to $430 \mathrm{~g} / \mathrm{kg} \mathrm{CWC}$ content (Table 3), may have been associated with the occasional tendency for cold-exposed sheep given clover pellets to bloat, and therefore may have been an indirect result of cold stress not typically observed with other forage diets.

Estimates of apparent or true digestion of $\mathrm{OM}$ in the stomach were previously shown to be positively related to the retention time of ${ }^{103} \mathrm{Ru}-\mathrm{P}$ (Kennedy et al. 1976, 1982). For chopped brome grass, a better prediction of OM digestion in the stomach was obtained when both the proportion of large particles in rumen digesta and ${ }^{103} \mathrm{Ru}-\mathrm{P}$ retention time were included as independent variables, indicating that the rate of comminution of large particles contributed significantly to retention time of digesta in the rumen and was inadequately represented by the marker, ${ }^{103} \mathrm{Ru}-\mathrm{P}$ (Kennedy et al. 1982). Another possible contributor to variation in the relation between digestion of $\mathrm{OM}$ in the rumen and ${ }^{103} \mathrm{Ru}-\mathrm{P}$ retention time might be the variability between animals in rate or ultimate extent of CWC digestion. Using nylon bags in vivo to incubate ground-diet preparations, a large standard error was found in the rate of CWC digestion (Table 2), but significant animal effects were not observed for rate of CWC digestion or in lag times. The enhanced rate of CWC digestion in nylon bags observed in sheep given pelleted diets when exposed to cold could not be readily explained and was not reflected in measured values of CWC flow at the duodenum.

The effects of cold stress on particulate markers $\left({ }^{103} \mathrm{Ru}-\mathrm{P}\right.$ and $\left.{ }^{51} \mathrm{Cr}-\mathrm{MP}\right)$ were different between grasses and legumes (Table 3). For the grasses, irrespective of dietary form, there was a greater decline in ${ }^{103} \mathrm{Ru}-\mathrm{P}$ retention time than for ${ }^{51} \mathrm{Cr}-\mathrm{MP}$, while the reverse tended to be true for lucerne and chopped clover. Because the ${ }^{51} \mathrm{Cr}$ label was mordanted on to particles which could pass the $1.0 \mathrm{~mm}$ screen, but were retained on the $0.5 \mathrm{~mm}$ screen during wet sieving in contrast to ${ }^{103} \mathrm{Ru}-\mathrm{P}$ which is carried mainly in the small particulate fraction (Dixon et al. 1983), it would be expected that there would be corresponding differences between grasses and legumes in the intermediate $(0.5-1.0 \mathrm{~mm})$ compared with the intermediate plus small $(<1.00 \mathrm{~mm})$ particles. Indeed it was calculated that the ratio, ${ }^{103} \mathrm{Ru}$ $\mathrm{P}:{ }^{51} \mathrm{Cr}$-MP retention times was inversely related to the $0.5-1.0 /<1.0 \mathrm{~mm}$ fraction $\left(r^{2} 0.59\right.$, $n 16$ ), indicating that relatively more of the intermediate-size particles escaped from the rumen of sheep given legumes than for sheep given grass diets during cold exposure. Thus the constraint to passage from the rumen of large and intermediate-size particles appeared to be less for legumes than for grass diets, in accordance with the findings of Moseley \& Jones (1979).

\section{Chewing behaviour}

The longer retention of ${ }^{51} \mathrm{Cr}$-MP caused by grinding and pelleting of diets, not evident for the liquid (CoEDTA) and ${ }^{103} \mathrm{Ru}-\mathrm{P}$ markers, was comparable to that observed by Wilkins et al. (1972) for large particles and indicative of the importance of rumination in comminution and passage of digesta particles of intermediate and large sizes. In the present experiment, rumination time in sheep given diets which had been ground through a $3.2 \mathrm{~mm}$ screen before pelleting was reduced to approximately 0.4 of values recorded for sheep given chopped diets, compared with a reduction to 0.2 when rye grass was ground through a $2 \mathrm{~mm}$ screen and wafered (Wilkins et al. 1972). However, the extra requirement for comminution of large digesta particles for sheep given chopped diets did not limit the capacity of the stomach to increase passage of digesta in response to cold stress. Previously we suggested (Kennedy et al. 1982) that effectiveness of rumination may have increased during cold exposure. Effectiveness of particle comminution during rumination could possibly increase due to a greater number of chews per $d$, or greater efficiency of comminution per chew. In the present experiment and in that of Weston (1983) for sheep given fixed intake of 
forages there was no evidence of any consistent increase in rumination, chews or duration attributable to cold exposure. Greater efficiency of comminution per chew could be achieved by variation of chews/cycle, by increased large particle content of the ruminated bolus relative to the rumen large particle pool, or by decreases in resistance to comminution or structural strength of the ruminated material. The present findings were insufficient to judge whether increased efficiency during comminution occurred, and indeed Kennedy (1983) suggested from the results of the present experiments that comminution during rumination of large particles of chopped canary grass in cold-exposed sheep could have been reduced owing to decreased microbial cellulolysis of CWC caused by nutrient deficiency. Given that cold stress per se had no effect on the upper size limit of particles which could escape from the rumen, and that rumination time and the number of chews per $d$ are presumed to limit forage intake (Van Soest, 1982), then the increased voluntary feed consumption of cold-stressed sheep given the chopped diets may simply reflect increased DM pool size or increased rate of passage of digesta, or both. The only pertinent findings for sheep are those of Weston (1983) and Chai et al. (1985) who found that rumen-fluid volume tended to be smaller, and rumination time tended to be longer for cold-exposed sheep allowed to express their voluntary feed consumption. The decline in rumination time per $\mathrm{kg}$ voluntary feed consumption in cold-exposed $v$. warm sheep was similar to that due to increased intake alone (Bae et al. 1979), and the response in voluntary feed consumption therefore was partly attributable to increased rumination effort during cold exposure.

The rates of contraction of the reticulum, and of eating, are consistently increased in cold exposure (Westra \& Christopherson, 1976; Gonyou et al. 1979; Welch et al. 1981; Weston, 1983; Chai et al. 1985). Both responses may be determined by the activity of the 'gastric centre' of the hypothalamus (Leek \& Harding, 1975). Calculations of the average value for DM entering the duodenum-reticulum contraction (Table 3) showed that the greatest flow occurred for sheep given canary grass pellets, with the least for sheep given chopped brome, with that for pelleted diets being 0.15 greater than for chopped diets, except for lucerne, in which pelleting caused little change. Greater passage of digesta per contraction in sheep given pelleted compared with chopped, and in warm $v$. cold-exposed sheep was observed. The former effect would be consistent with increased opportunity for finely-divided digesta to pass from the rumen. The reduction of flow per contraction in cold-exposed sheep may be related to depression of rumen volume, as it has been suggested (Freer et al. 1962) that the positive relation between the weight of OM transferred to the omasum per reticular contraction and level of intake of OM may be due to changes in rumen volume. However, lower DM flow per contraction was found in cold-exposed sheep given clover pellets despite the postulated increase in rumen pool size (see p. 170). Measurements on sheep at ad lib. feeding conditions are required to clarify the situation.

\section{VFA patterns}

The effects of cold exposure on VFA patterns in the present experiment were similar to those already observed, i.e. decreased acetic acid and increased propionic acid molar proportions (Kennedy et al. 1976; Kennedy \& Milligan, 1978). Molar proportions of isovaleric acid were also reduced by cold exposure and by pelleting, probably as a consequence of decreased degradation of dietary protein (El-Shazly, 1952) caused by decreased retention time of dietary protein in the rumen, and perhaps by heat treatment during pelleting. Increased propionic acid: acetic acid values are correlated with decreased digestion of CWC relative to other sources of fermentable OM, and may be due to restriction on methanogen numbers caused by increased rate of rumen turnover (Van Soest, 1982). Methane production in the rumen has been observed to decrease in sheep exposed to cold and should increase the energetic efficiency of cold-exposed ruminants (Kennedy \& Milligan, 1978). Reduction in 
VFA concentration in cold-exposed sheep occurred in the present experiment, although no such effect was observed by Kennedy \& Milligan (1978) and R. H. Weston (personal communication); however, in the latter experiment production rate of VFA and VFA pool size were reduced. The significant increase in rumen $\mathrm{pH}$ observed in the present experiment is also in agreement with decreased VFA production rate during cold exposure.

\section{$O M$ digestion in intestines}

Direct comparisons between sheep given pelleted and chopped forms of the same ration in the present experiment did not yield differences in intestinal OM digestibility of digesta entering the duodenum, consistent with the lack of effect of dietary form or ambient temperature on intestinal retention time of ${ }^{103} \mathrm{Ru}-\mathrm{P}$. An interaction between ambient temperature and dietary form of brome grass postulated after comparing results across experiments (Kennedy et al. 1982) was not supported by the present results. For sheep given chopped clover, cold exposure caused a significant increase $(P<0.05)$ in the intestinal digestion of OM (Table 2). Sheep given clover also had high contents of large particles in duodenal digesta. In addition, for the chopped-clover diet used in this experiment, intestinal CWC digestion of digestible CWC flowing into the duodenum appeared to be nearly complete, in agreement with the compensatory increased intestinal digestion when red clover was ground and pelleted (Beever \& Thomson, 1982) or when digestion of red clover was compared with that of rye grass (Moseley \& Jones, 1979).

\section{Voluntary feed consumption}

The difference in the effects of cold exposure on voluntary feed consumption of sheep given chopped and pelleted forms of the diets was notable, although it is recognized that sheep were given only a limited time to adapt to ad lib. conditions. Increased intakes of pelleted brome and canary grass of cold-exposed sheep have been observed after 2 weeks (Kennedy et al. 1985). Results from these and other experiments indicate that increased intake of chopped diets by non-pregnant and non-lactating ruminants occurs as a result of increased passage of digesta from the stomach and increased rumination effort, but not of increased rumen capacity, rate of digestion of plant cell walls in the rumen, nor of lifting of constraints to passage of medium and large particles from the rumen. For pelleted diets, the limitation to increased intake is probably at the postrumen level (Campling, 1970), mediated through feedback controls on stomach motility from tension receptors in the omasum, abomasum and duodenum (Leek \& Harding, 1975). Increased intestinal absorption of non-ammonianitrogen in the intestines relative to digestible OM intake may also contribute to increased voluntary feed consumption of chopped forages in cold-exposed sheep (Christopherson \& Kennedy, 1983).

Financial support was provided by the Natural Sciences and Engineering Research Council of Canada and the Agricultural Research Council of Alberta. Dr R. J. Christopherson and $\mathrm{Mr}$ J. Kelly helped with animal sampling. Statistical advice and analyses were provided by Dr R. Hardin, Mr G. Godby and Mrs I. Vlach.

\section{REFERENCES}

Bae, D. H., Welch, J. G. \& Smith, A. M. (1979). Journal of Animal Science 49, 1291-1299.

Beever, D. E. \& Thomson, D. J. (1982). Grass and Forage Science 36, 211-219.

Campling, R. C. (1970). In Physiology of Digestion and Metabolism in the Ruminant, pp. 226-235 [A. T. Phillipson, editor]. Newcastle upon Tyne: Oriel Press.

Chai, K., Kennedy, P. M., Milligan, L. P. \& Mathison, G. W. (1985). Canadian Journal of Animal Science 65, (In the Press.) 
Christopherson, R. J. \& Kennedy, P. M. (1983). Canadian Journal of Animal Science 63, 477-496.

Dixon, R. M., Kennelly, J. J. \& Milligan, L. P. (1983). British Journal of Nutrition 49, 463-473.

Dixon, R. M. \& Milligan, L. P. (1985). British Journal of Nutrition 53 (In the Press.)

El-Shazly, K. (1952). Biochemical Journal 51, 647-653.

Faichney, G. J. (1975). In Digestion and Metabolism in the Ruminant, pp. 277-291 [I. W. McDonald and A. C. I. Warner, editors]. Armidale: University of New England Publishing Unit.

Freer, M., Campling, R. C. \& Balch, C. C. (1962). British Journal of Nutrition 16, 279-295.

Gonyou, H. W., Christopherson, R. J. \& Young, B. A. (1979). Applied Animal Ethology 5, 113-124.

Kennedy, P. M. (1983). Proceedings of the New Zealand Society of Animal Production 43, 123-125.

Kennedy, P. M., Christopherson, R. J. \& Milligan, L. P. (1976). British Journal of Nutrition 36, $231-242$.

Kennedy, P. M., Christopherson, R. J. \& Milligan, L. P. (1982). British Journal of Nutrition 47, $521-535$.

Kennedy, P. M., Christopherson, R. J. \& Milligan, L. P. (1985). VI International Symposium on Ruminant Physiology, (In the Press.)

Kennedy, P. M. \& Milligan, L. P. (1978). British Journal of Nutrition 39, 105-117.

Leek, B. F. \& Harding, R. H. (1975). In Digestion and Metabolism in the Ruminant, pp. 60-76. [I. W. McDonald and A. C. I. Warner, editors]. Armidale: University of New England Publishing Unit.

McDonald, I. (1981). Journal of Agricultural Science, Cambridge 96, 251-252.

Moseley, G. \& Jones, J. R. (1979). British Journal of Nutrition 42, 139-147.

Shipley, R. A. \& Clark, R. E. (1972). Tracer Methods for In Vivo Kinetics. New York and London: Academic Press.

Sokal, R. R. \& Rohlf, F. J. (1969). Biometry. San Francisco: W. H. Freeman \& Co.

Tan, T., Weston, R. H. \& Hogan, J. P. (1971). International Journal of Applied Radiation and Isotopes 22, $301-308$.

Thomson, D. J. \& Beever, D. E. (1980). In Digestive Physiology and Metabolism in Ruminants, pp. 291-308

[Y. Ruckebusch and P. Thivend, editors]. Lancaster: MTP Press.

Uden, P., Colucci, P. \& Van Soest, P. J. (1980). Journal of the Science of Food and Agriculture 31, $625-632$.

Van Soest, P. J. (1982). Nutritional Ecology of the Ruminant. Corvallis: O \& B Books Inc.

Waldo, D. R., Smith, L. N., Cox, E. L., Weinland, B. T. \& Lucas, H. L. (1971). Journal of Dairy Science 54, 1465-1469.

Weich, J. G., Paimer, R. H. \& Gilman, B. E. (1981). Journal of Animal Science 55 suppl 1, 474.

Weston, R. H. (1983). Proceedings of the Nutrition Society of Australia 8, 181-184.

Westra, R. \& Christopherson, R. J. (1976). Canadian Journal of Animal Science 56, 699-708.

Wilkins, R. J., Lonsdale, C. R., Tetlow, R. M. \& Forrest, T. J. (1972). Animal Production 14, 177-188. 